\title{
Chapter 12 \\ Reimagining Sex Work Venues: \\ Occupational Health, Safety, and Rights in Indoor Workplaces
}

\author{
Brooke S. West, Liz Hilton and Empower Thailand, Anne M. Montgomery, \\ and Allison R. Ebben
}

\section{Introduction}

The physical space where sex work occurs, and its social, economic, and policy context, greatly influences sex workers' health and safety [1,2]. Although the dynamics of sex work vary widely, categorisation of sex work is typically based on indoor versus outdoor settings. Indoor settings may include brothels, hotels, entertainment venues (like bars and clubs), or even private homes. Outdoor settings, parks, truck stops, or the interiors of vehicles, for instance, are generally associated with street-based sex work. However, this distinction paints broad strokes, and the reality is far more complicated since participation in sex work is often fluid, involving elements of both indoor and outdoor work. For example, clients may be solicited on the street, in bars, or through online ads, and then sex may be exchanged in a hotel, vehicle, home, or elsewhere.

An appreciation of the diversity of sex work environments is important in understanding the factors that may either lead to increased health risks or serve as protective factors [3]. In particular, understanding how the unique features of sex workers' occupational conditions differ across the multiple venues where sex work practised

\author{
B. S. West (凶) \\ School of Social Work, Columbia University, New York, NY, USA \\ e-mail: bsw2110@columbia.edu \\ Liz Hilton and Empower Thailand \\ Empower Foundation, Chiang Mai, Thailand \\ e-mail: lizempower322@gmail.com
A. M. Montgomery
Department of Health Studies, Haverford College, Haverford, PA, USA
e-mail: amontgomer@haverford.edu

\author{
A. R. Ebben \\ School of Social Work, Columbia University, New York, NY, USA \\ e-mail: are2129@columbia.edu
}


is essential to developing and supporting programmes that promote and support the rights, health, and safety of sex workers [3]. Operating in isolated or dark locations has been shown to increase risk of violence and to limit sex workers' negotiating power with clients [4-10]. The increased visibility of working in public spaces may also increase the likelihood of sex workers experiencing negative encounters with law enforcement and stigma from community members [11, 12] which, in turn, can limit their agency and displace sex workers to more dangerous settings $[8,9,13]$. Sex workers' ability to access health and harm reduction services can also depend on the sex work setting $[5,6]$. Although some sex work locations afford greater protection from a range of health risks, venues differ widely, and disparities in levels of concealment, control, and isolation make both outdoor and indoor settings potential sites of either risk or safety [14].

So what factors are meaningful when trying to understand sex workers' health and rights in the context of physical environments where sex work takes place? In this chapter, we focus primarily on indoor workplaces, and examine the unique social, physical, economic, and policy characteristics that increase or mitigate harm for sex workers. By "indoor workplaces," we mean the broad range of indoor venues in which either solicitation or sex with clients occurs. We propose the following broad categories of indoor sex work venues shown in Table 12.1 [adapted and expanded from Harcourt and Donovan [11]]: brothels, entertainment venues, service venues (e.g. massage parlours and bathhouses), rented rooms, private residences, and virtual (e.g. online) venues. These spaces vary in terms of how explicitly the venue is dedicated to sex work, location of solicitation and delivery of sexual services, levels of regulation, occupational standards and protective measures employed, and potential threats to sex worker health and safety (discussed in greater detail in the next section).

The goals of this chapter are, therefore, to: (1) elucidate factors that influence the well-being of sex workers in indoor workplaces; (2) provide a case study of sex worker-led initiatives to enhance workplace health and rights, focusing on the organisation Empower Thailand and the affiliated Can Do Bar; (3) describe best practices for indoor settings; and (4) develop a framework of key social, economic, physical, and policy factors that support sex worker efforts to organise and promote rights, health, and safety. The chapter will bring together research from global contexts to illuminate critical challenges facing sex workers in indoor venues, as well as suggest opportunities to advance comprehensive programmes and policies.

\section{Health, Safety, and Rights of Sex Workers in Venues}

Much of sex work-related health programming has focused on HIV/STI prevention. Although important, this singular focus may reinforce harmful notions that sex workers are vectors of disease, thus undercutting more holistic support for overall occupational health and human rights. In reality, sex workers' health needs are diverse. Sexual health concerns extend beyond HIV/STIs to include pregnancy, 
Table 12.1 Categories of indoor venues

\begin{tabular}{|c|c|c|}
\hline $\begin{array}{l}\text { Indoor venue } \\
\text { category }\end{array}$ & Description & Special considerations \\
\hline Brothels & $\begin{array}{l}\text { Premises explicitly dedicated to } \\
\text { providing sexual services: Clients } \\
\text { solicited on site or through other } \\
\text { means (e.g. online); sex conducted } \\
\text { on site. }\end{array}$ & $\begin{array}{l}\text { Most likely licensed and state } \\
\text { regulated. } \\
\text { Can afford sex workers greater } \\
\text { control over sexual exchange, reduce } \\
\text { exposure to violence or police } \\
\text { interactions, and provide } \\
\text { opportunities for health care } \\
\text { (depending on managerial and/or } \\
\text { owner practices, plus legal context). }\end{array}$ \\
\hline $\begin{array}{l}\text { Entertainment } \\
\text { venues }\end{array}$ & $\begin{array}{l}\text { Bars, clubs, dance halls, karaoke } \\
\text { clubs, beer halls, cafes: Premises } \\
\text { dedicated to serving alcohol. Clients } \\
\text { solicited in venue; sex conducted on } \\
\text { or off site. }\end{array}$ & $\begin{array}{l}\text { - May be licenced and state regulated. } \\
\text { - Presence of alcohol and drugs can } \\
\text { decrease women's negotiating power } \\
\text { and increase exposure to violence. }\end{array}$ \\
\hline Service venues & $\begin{array}{l}\text { Saunas, massage parlours, } \\
\text { bathhouses, salons, or barber shops: } \\
\text { Premises dedicated to providing } \\
\text { other services, but range of sexual } \\
\text { services are provided. Clients } \\
\text { solicited in venue; sex conducted on } \\
\text { or off site. }\end{array}$ & $\begin{array}{l}\text { - May be licenced and state regulated. } \\
\text { Presence of alcohol and drugs can } \\
\text { decrease women's negotiating power } \\
\text { and increase exposure to violence. } \\
\text { - Indirect nature of sex work may } \\
\text { make it less safe. }\end{array}$ \\
\hline Rented rooms & $\begin{array}{l}\text { Hotels, guesthouses, or other rented } \\
\text { rooms: Clients solicited on the street } \\
\text { or through other means (e.g. street, } \\
\text { entertainment venues); sex conducted } \\
\text { in rented room. }\end{array}$ & $\begin{array}{l}\text { Work may be conducted alone with } \\
\text { little control over the work } \\
\text { environment. } \\
\text { Exposure to violence and police } \\
\text { interactions may be higher and } \\
\text { access to services lower. }\end{array}$ \\
\hline $\begin{array}{l}\text { Private } \\
\text { residences }\end{array}$ & $\begin{array}{l}\text { Clients solicited through multiple } \\
\text { means (e.g. phone, street, online); } \\
\text { sex work conducted in private } \\
\text { homes, either that of the sex worker, } \\
\text { client, or someone else. }\end{array}$ & $\begin{array}{l}\text { Work may be conducted alone, } \\
\text { which can increase exposure to } \\
\text { violence. } \\
\text { - Greater control over work } \\
\text { environment and client selection can } \\
\text { mitigate risks. } \\
\text { May be more covert, which can } \\
\text { reduce negative police and } \\
\text { community interactions. }\end{array}$ \\
\hline Virtual venues & $\begin{array}{l}\text { Clients solicited through online } \\
\text { means or newspapers; sex work } \\
\text { conducted in rented room, private } \\
\text { residence, brothel or other venue. }\end{array}$ & $\begin{array}{l}\text { Work may be conducted alone, } \\
\text { which can increase exposure to } \\
\text { violence. } \\
\text { Greater control over work } \\
\text { environment and client selection can } \\
\text { mitigate risks. } \\
\text { May be more covert, which can } \\
\text { reduce negative police and } \\
\text { community interactions. }\end{array}$ \\
\hline
\end{tabular}


maternal morbidity and mortality, and access to safe abortion (e.g. pre- and postabortion care), as well as bladder and kidney infections. Repetitive stress injuries to wrists, arms, shoulders, jaws, knees, feet, and backs, resulting from repeated "hand jobs", "blow jobs", working on inadequate beds, and working in high heels, are also matters of concern [15]. Chronic and noncommunicable health conditions like heart disease and diabetes may also be important challenges for sex workers, as these conditions can be exacerbated by chronic stress and trauma [16], as experienced by some sex workers.

Sex workers in practically all settings face substantial risk of sexual, psychological, and physical violence from clients, partners, police, managers, strangers, neighbours, and other sex workers. These abuses include harassment, condom refusal, rape, sexual assault, physical assault, drugging, abduction, trafficking, and murder [17]. Violence further manifests as robbery, non-payment by clients, and extortion by police, managers, pimps, landlords, and others $[17,18]$. The health and safety of sex workers are also jeopardised by disproportionate experiences of structural violence, including stigma, discrimination, poor occupational conditions, high rates of policing, and systematic economic and social marginalisation, leading to higher rates of homelessness and poverty [8, 19]. These experiences can contribute to a greater risk of sex workers developing a range of mental health conditions, like PTSD, depression, anxiety, suicide, and alcohol and drug use disorders [17, 20], as well as work-related stress [21, 22].

All of these occupational health and safety issues are compounded by reduced access for sex workers to needed health and social services due to limited availability of such services, prohibitive costs of services, and discriminatory practices preventing sex workers from receiving or seeking quality care [23]. These factors, as they relate to indoor venues, are discussed below.

\section{Physical Characteristics}

Indoor venues may provide sex workers with higher levels of safety compared to other environments. This depends, however, on the specifics of the particular space-who is in charge and how the space is run. Although some indoor spaces utilise protective measures, like security guards, good lighting, and panic buttons, others may be highly disordered, lacking in basic hygiene, or located in isolated areas where risks are exacerbated. For instance, working in a brothel or other indoor venue may mean greater protection from police if the manager or owner pays police to leave employees alone [24]. Managers and other third parties (e.g. security guards) can help to screen and regulate clients and enforce policies to enhance sex worker control over sexual negotiations [19, 24, 25]. For instance, in entertainment venues where alcohol is served, managers may offer "ladies' drinks" with reduced alcohol content, thus potentially decreasing levels of intoxication among female workers, which in turn enables them to better negotiate their health and safety with clients [26]. If workplace policies are designed to support safer sex, indoor spaces 
may also afford greater access to sexual health information and services, as well as promoting the use of condoms [19, 27-29].

However, the extent to which managed indoor venues are supportive of sex workers' health, rights, and independence depends on the practices, policies, and regulations characterising a particular venue. In venues where sex workers are pressured to work quickly or to service a large number of clients in a short period of time, their agency to negotiate condom use and safety with clients may be limited $[30,31]$. Additionally, in some indoor venues, pressure on sex workers to drink or use drugs may inhibit their agency when negotiating condom use and increase the risk of exposure to violence [26, 32]. More broadly, managers and owners of indoor venues in settings where sex work is criminalised may not view sex workers as employees with rights and entitlement to a safe working environment, and some even leverage the criminalisation of sex work to exploit their employees [33]. Thus, some sex workers prefer the freedom of working independently, outside of the regulation and surveillance of indoor venues [34].

\section{Economic Factors}

Economic factors operate in many ways to shape the health and well-being of sex workers, and poor socio-economic conditions often underlie entry into sex work [35]. Economic injustices experienced by sex workers include limited economic opportunities, low pay, their performing dual roles as primary caretakers and sole breadwinners, as well as, for marginalised groups, limited access to property ownership, education, banking, and financial management. This economic vulnerability has been shown to increase workers' vulnerability to having sex without condoms, reduce their negotiating power with clients, and increase gender-based violence and risk for HIV/STI [35-37]. Similarly, studies have shown that residential instability or homelessness increases experiences of sexual and physical violence $[6,38]$. Economic vulnerability stemming from the criminalisation of sex work (manifesting in, for example, clients refusing to pay, or police extorting bribes or fines from workers attempting to avoid arrest), in particular, also results in lower rates of condom use and higher risks of HIV infection [35, 38-45].

Indoor sex work venues may be attractive to sex workers if they are able to charge higher fees and/or see more clients, especially if the setting also provides greater protection from police or clients $[4,8,9]$. However, there are variations to the economic benefits and risks sex workers experience within indoor sex work venues. Many sex workers find themselves paying tips or fees to third parties such as managers, owners, drivers, front desk workers, security staff, or phone operators [46]. In some contexts, sex workers report these relationships with third parties to be supportive, whereas in others, economic arrangements with third parties may be reported as being financially exploitative or as creating situations where sex workers are required to pay exorbitant fees to work in these spaces [46] or to procure clients [47]. Such economic interference cuts into workers' earnings and may lead some to 
sacrifice the relative safety of such workplaces for riskier settings where they have greater autonomy over their money, time, and working conditions [19]. Importantly, these exploitative relationships are most likely to occur in jurisdictions where sex work is criminalised, a factor underscoring the urgent need for sex worker labour rights. Ultimately, sex workers should be equally free to choose to work with third parties or to work independently, and, furthermore, to do so without the unjust criminalisation of third parties based on assumptions of trafficking or exploitation.

\section{Social Factors}

Social factors also shape health, safety, and rights outcomes for sex workers in indoor sex work venues. For example, due to the highly stigmatised and often criminalised nature of sex work, health care and legal services may be harder to obtain for sex workers than for workers in other industries [48]. The stigma against sex workers is often entrenched in unjust power structures that treat sex workers as deserving of scorn or abuse [49]. This results in high rates of violence against sex workers. In one global sample, $45-75 \%$ of sex workers reported lifetime prevalence of workplace violence [50]. However, working in an indoor venue, as opposed to working outdoors, may offer some protection against stigma by making it easier for individuals to conceal their sex worker status from the public and police.

Within indoor workplaces, sex workers engage with a host of factors that support or negate their health and safety. Managerial promotion of supportive policies (e.g. intervening with bad clients), provision of health information and condoms, and deterrence of unjust policing practices, can lead to reduced violence against sex workers and to their experiencing greater agency with clients $[9,19,24,25,27-30$, 51]. However, managers may also interfere with negotiations regarding condom use, client selection, and pricing [10, 19, 30, 31, 33, 52]. Relationships with other sex workers can also improve sex worker health. Positive aspects of support include the sharing of information about clients (e.g. Ugly Mugs reports and "bad date lists"), HIV testing, and strategies to negotiate safe sex and condom use, as well as the establishment of supportive venue norms and opportunities for sex workers to organise against exploitative managerial practices [27-29].

In contrast, limited peer support, either as a result of competition between workers or venue policies limiting cooperation between them, can lead to their experiencing greater isolation and limited power to address issues of occupational health and safety $[10,25,30,53]$. Importantly, the criminalisation of sex work and related stigmas can stand in the way of the development of supportive relationships with management, as well as collective action among sex workers [54, 55]. 


\section{Policy Environment}

All of the factors discussed above intersect with policy environments in ways which impact sex workers' health and safety. Globally, four primary legal models exist, varying in levels of regulation and criminalisation of sex work: (1) Prohibition criminalises both the selling and buying of sex and third party involvement; (2) End Demand laws criminalise paying for sex, or organising or profiting from prostitution on the part of third parties, but do not criminalise the selling of sex; (3) Legalisation and regulation may involve the partial decriminalisation of some forms of sex work, but often introduce oppressive venue licensure and regulation under administrative and labour laws; and (4) Decriminalisation removes all punitive laws from both the selling and buying of sexual services, as well as from third parties or others who are directly or indirectly involved in the sex industry [56].

Most countries adopt legislation informed primarily by the lens of prohibition, resulting in the widespread criminalisation of sex work around the world. Even in contexts where sex work is quasi-legal or legal, may activities associated with sex work still remain criminalised. This impacts third party actors who profit from sex work by, for example, running an establishment, providing security, spotters, etc. [57], or maintaining online advertising platforms, which were directly affected by the 2018 FOSTA-SESTA legislation in the United States [58]. In some contexts, family members and cohabitants can be charged with "living off the proceeds of prostitution" [57]. These restrictions have substantial impact on the health, safety, and rights of indoor sex workers [19, 23, 42, 59-61]. At the broadest level, laws regulating sex work exacerbate stigma and force sex work underground, making it hidden and less safe for individuals engaged in this work.

The criminalisation, regulation, and policing of sex work are documented to lead to human rights abuses, including workplace raids, harassment, arrests, rape, confiscation of condoms, and extortion of bribes or sexual favours by police [10, 49, 62, 63]. The collective result of these outcomes is a direct impact on sex worker health, through experiences of physical and sexual violence, decreased access to condoms and condom use, fear of carrying safer sex or injection supplies due to threat of arrest, increased risk for HIV/STIs, reduced negotiating power with clients, and fear of accessing health services, alongside the creation of a climate where economic vulnerability is systemic $[49,62,63]$. Without legal protection, experiences of violence, abuse, or exploitation from police, clients, or other parties, may not be investigated or registered, plus sex workers may avoid reporting violence for fear that they themselves will be charged $[12,64]$. The stringent or coercive regulation of indoor spaces can push individuals to work in unsafe indoor or outdoor workspaces, where they have less ability to screen or negotiate with clients $[5,9,19,65]$. In other words, the potential protective effects of working in indoor spaces are undermined by policies related to the regulation and criminalisation of sex work [4]. 


\section{Additional Considerations}

Stigma, violent policing, and criminal penalties are disproportionately experienced by other marginalised communities_-people whose identities may intersect with sex worker identities - including people who use drugs; migrants, Indigenous people, and other racialised minorities; people living with HIV; LGBT populations; individuals experiencing homeless or unstable housing; and populations with cooccurring health issues like mental illness. People who use drugs, especially those who inject, often face substantial stigma within indoor venues, resulting in their experiencing social isolation or being pushed outdoors to the margins of communities where their income is lowered and the possibility of experiencing violence is increased [2, 8, 49, 66, 67]. Individuals who are drug-dependent or intoxicated may be less able to negotiate condom use or safer injection, may be more likely to have sex without condoms to access money or drugs, and may be less able to extricate themselves from dangerous situations with clients [4, 23]. As well, the double stigma and marginalisation associated with sex work and substance use can translate into sex worker avoidance of health and social services, and elevated levels of police harassment, abuse, and imprisonment [68].

Migrant sex workers also face compounded risks. Working in indoor venues may be particularly attractive to migrant sex workers as a way to overcome challenges associated with their migrant status (e.g. social isolation, barriers to health and legal protections, language barriers, the need to remain less visible) [54, 69]. During raids on venues, however, migrant sex workers may be disproportionately targeted and find themselves at risk of deportation if their legal status is discovered by authorities [70]. Protection of sex workers' labour is limited across the board, and for migrant sex workers in indoor venues, it may be even more so if they fear reporting or discussing workplace violations due to concerns around disclosure of their immigration status $[61,65]$. Broadly speaking, migrant populations may not be afforded the same rights as citizens, which can prevent them from seeking health or social services or soliciting help from the police if they experience abuse or violence $[65,71]$.

Similarly, transgender sex workers may be marginalised within sex work communities, excluded from indoor spaces, and thereby forced to work in street settings. Transgender sex worker's safety is already threatened by stigma and discrimination: they face greater exposure to physical and sexual violence, as well as greater economic vulnerability and diminished ability to negotiate with clients [72-77]. The hypervisibility and policing of trans bodies, combined with a failure to address threats to trans sex workers, means the creation of safer indoor working environments is important to protecting the rights of trans sex workers [76, 77]. Given these structural vulnerabilities, greater attention needs to be directed towards the specific health, rights, and safety concerns of diverse and marginalised sex workers in indoor venues. 


\section{Case Study of Empower Thailand}

Empower Thailand, a sex worker-led human rights and women's advocacy group, was born in 1985 in the go-go bars of Patpong, the famous red-light district of Bangkok. Empower currently works across five Thai provinces. In Chiang Mai, our organisation does weekly outreach, visiting over 250 sex work sites and 3000 sex workers each month. Over the last 2 years, we have added "internet outreach" where news and information are shared by hundreds of sex workers in mobile app groups. The following section will detail key components of our innovative approach to addressing health, rights, and safety in indoor sex work venues.

Sex workers make up most of the leadership of Empower and are regularly invited to guide and critique our activities and advocacy work. Empower focuses on five domains:

1. Community: Empower is part of and central to the sex worker community. We use our space to celebrate, mourn, play, eat, and organise together.

2. Legal: We learn, analyse, and critique the laws that impact us.

3. Art: We use art and performance to strengthen our advocacy.

4. Education: We provide education for society about human rights, justice, and sex work from our collective experience. We also provide sex workers with access to education (e.g. literacy, language training, school qualifications, job skills).

5. Health: We teach the public and health providers about best practices when working with sex workers and provide a setting wherein sex workers can share health knowledge and referrals with one another.

As a collective of sex workers who are experts in what is most important to our community we have numerous insights into what supportive interventions look like, as well as into which activities might involve unintentional, negative consequences for sex workers. The lessons we share below are rooted in the need for health and rights promotion focusing on occupational health and safety (OHS), and support for sex worker organising.

Prioritising Collective Organising: Reimaging Outreach as In-reach Empower started with women visiting each other's workplaces and coming together to talk, share skills, and reflect on their lives. It was not then called "outreach", a term imported years later from the NGO world. Empower outreach has always been more like "in-reach", as we are part of the communities we visit. As Empower Sex Worker Member 1 states:

We are sex workers on outreach. We don't use the term 'peer', as it has become a word used by NGOs to separate sex workers from each other unnecessarily. It also is a trap where sex workers can be used as "peer educators" for NGOs, but we can still not be in the decisionmaking roles and high paid positions of Director, Coordinator, Administration Officer, etc.

For Empower, outreach (or in-reach) is not just an activity or project; it is the vital component of every activity and programme. Empower does outreach to build and solidify community, have fun, catch up with old friends, and introduce Empower 
to new sex workers in the area. It is also a means for sharing news and experiences among diverse sex workers and for ensuring that Empower's activities and advocacy are responsive to the changing work conditions, needs, and interests of sex workers. As Empower Sex Worker Member 2 shares:

\begin{abstract}
We went on outreach to share Empower plans to make a submission to the government to repeal the Prostitution Act. However, everywhere we went sex workers were talking about the terrible economy ... worrying about having enough money to buy kids shoes, cover school fees, rent etc. The Prostitution Act felt a long way from real life. So we decided to start running a monthly second-hand clothes market at Empower. The market not only cut down on living expenses, but also gave us a chance to gather together and make it clear to each other that the Prostitution Act is the reason that about a quarter of our monthly earnings are stolen in bribes. We were able to get more sex workers supporting the lobbying for law reform. We only knew we needed to make the link clear because of what we learned on outreach.
\end{abstract}

Each month, sex workers create a pamphlet to distribute in the community that includes information about our educational programmes, upcoming Empower activities, and information on the law, human rights, or health. Pamphlets display the Empower "Honey Bee" logo to make them easily recognisable to sex workers with limited literacy; we also use large lettering so they can be read in the dim light of indoor workplaces. Using the vibrant language of sex workers, rather than academic or NGO language, each pamphlet is designed with the knowledge that it may be read by employers, customers, police, or family members, so we ensure information will not embarrass or endanger sex workers. According to Empower Sex Worker Member 3:

No restaurant or their staff would want people handing out graphic descriptions and pictures of food poisoning. We also don't want pamphlets about gonorrhea passed to us at work, especially in front of our customers.

Sex workers pair up to plan and conduct outreach. We wear Empower t-shirts so our mission is clear to other sex workers and their employers. When we enter establishments, we are good customers and take a seat, order a drink, and when workers have time they pick up a pamphlet, exchange gossip and get condoms. In venues where it is not possible to sit (e.g. some massage parlours), we leave pamphlets. For many sex workers, meeting Empower on outreach is the first step to becoming community organisers and "high-heeled defenders". Over the last three decades, more than 50,000 sex workers have joined Empower, most of whose first experience of Empower was an outreach visit to their workplace.

\title{
Respecting Sex Workers as Workers and Venues as Workplaces and Places of
}

Business Entertainment venues are, first and foremost, workplaces, and sex workers are there to earn their living. We learned from experience that it is not appropriate to attempt training, workshops or HIV/STI testing in these venues during business hours; instead, we use outreach to invite sex workers to attend events away from the workplace and outside working hours.

As outreach workers, sex workers have insider knowledge of the routines, working conditions and social composition of different venues (e.g. literacy levels, 
gender identity, migration status, incomes). This allows us to tailor outreach to safely and respectfully approach sex workers. In particular, Empower understands power dynamics in different types of workplaces, allowing us to avoid complicity with exploitative employers or reinforcing bad labour and human rights practices. As one Empower member notes:

The [NGO] staff don't really talk to us, they usually just talk to the mamasan (manager). The mamasan doesn't want any trouble from the health department so she's nice to them. She shouts out "Girls come and get your blood tested!" Can we refuse? Technically yes, it's supposed to be voluntary, but if we refused all our friends would look at us and wonder why we don't want a test. The mamasan would be angry so we may get our salary cut. The [NGO] staff would want us to explain why we are refusing and try to talk us into a test. It seems that the test is not mandatory but volunteering for it is! We call it forced voluntary testing. No one is doing this testing for our health, not even us.

Outside projects that develop primary relationships with management rather than with workers can lead to activities and projects that rely on coercion and fear. This may result in forced HIV/STI testing, forced participation in research, and workers left unable to speak honestly or freely to health providers.

\section{The Can Do Bar: A Just and Fair Workplace for Sex Workers, by Sex} Workers In many contexts, sex worker projects began as HIV/AIDS outreach; however, sex worker concerns extend far beyond disease prevention and include issues of stigma, labour rights, decriminalisation, and health promotion. After 2005, Empower began focusing more widely on Occupational Health and Safety (OHS) for sex workers in entertainment places. This involved running a series of workshops bringing together sex workers and OHS experts to discuss concerns and solutions related to salary cuts, customer quotas, mandatory alcohol consumption, long work hours, lack of paid leave or days off, locked fire escapes, harmful noise levels, and inadequate toilet facilities. Findings were published in an OHS handbook for sex workers and business owners to assess their workplaces and implement changes. In the Empower drop-in centre, sex workers also designed a model of the working conditions outlined in the manual.

In 2006, frustrated by public and policymaker resistance to improving working conditions, a group of sex workers from Empower created their own venue-an entertainment space developed for sex workers by sex workers to demonstrate the conditions they were demanding. They named it the "Can Do Bar" because they believed it was possible for sex workers to do it themselves. A fund was established where contributing sex workers became part of the collective ownership. The price of a share was set at 1000 Thai Baht (US\$33). Those who could not afford monetary contributions could join the collective by contributing labour to the design and construction of the bar. Within months, the fund had raised over 1 million Thai Baht (approximately US\$35,000).

The Can Do Bar was opened on September 19th, 2006 and was informed by national OHS, labour, and business standards (see Box 12.1). The collective committed to several core principles: the Can Do Bar would work within the law and not pay bribes to police; sex would be for personal income and not for the profit of the 


\section{Box 12.1 Working conditions at the can do bar- "Can Do- Experitainment" (2006)}

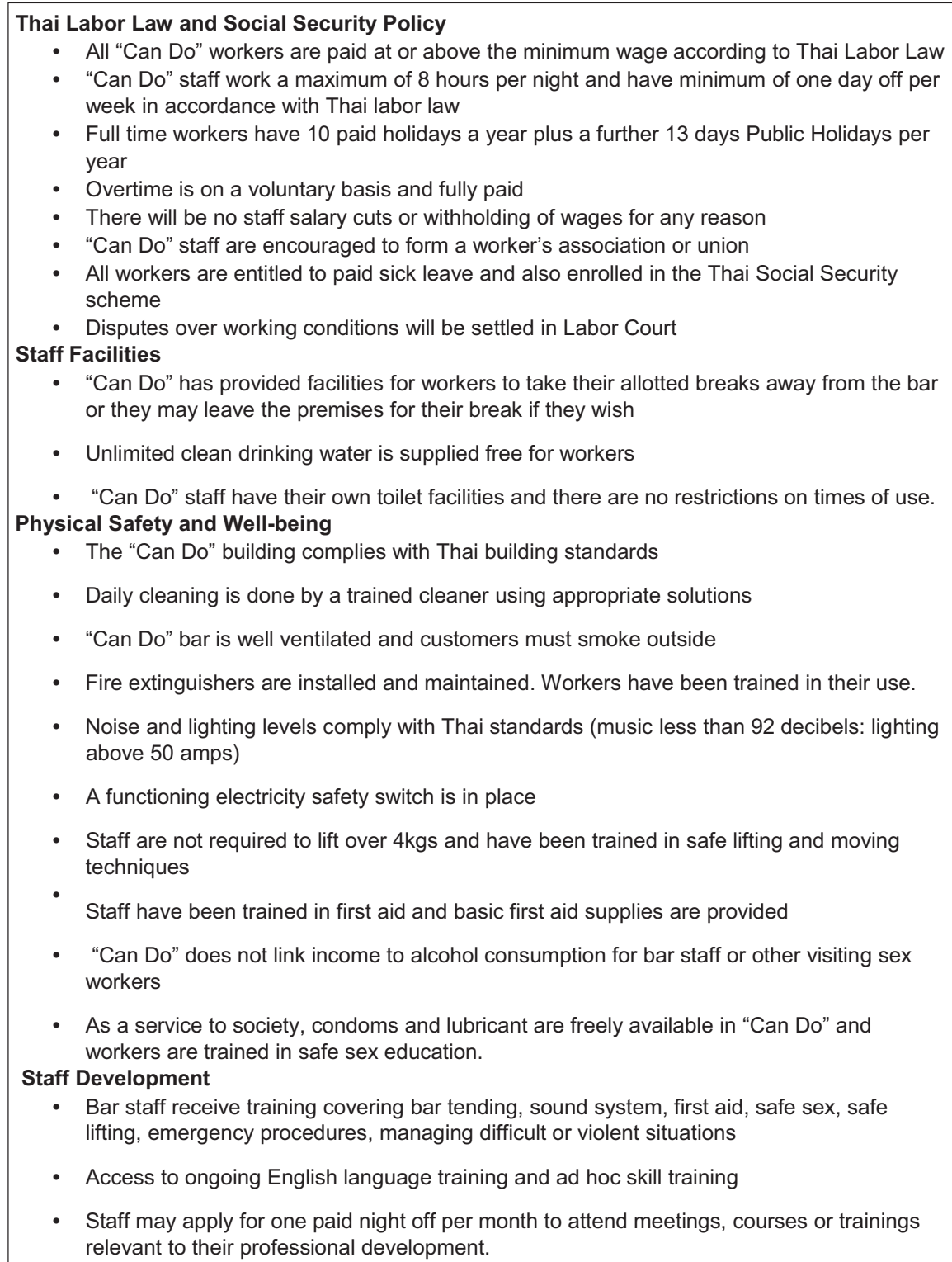

bar; visiting sex workers unaffiliated with Empower would be welcome and free to engage with other customers; and decision-making would be done by consensus among Empower members. Importantly, the Can Do Bar could not function without the collective spirit of sex workers working together. For instance, each year, sex workers involved in the Can Do Bar collectively undertake financial planning. 
To date, they have decided to reinvest profits to maintain and improve the bar rather than divide profits among themselves.

The success of the Can Do Bar cannot be measured in profits alone, however, as our work impacts women's health and livelihood. It also sends a message to other entertainment venues, policymakers, health officials, and to the general public. For example, the Can Do Bar has helped to promote social security for sex workers, enrolling almost 400 women in the Thai Social Security Scheme, which provides workers with unemployment payments, health care, old age pensions, and childcare payments. Encouraged by this example, sex workers at other venues have successfully demanded that their employers also enrol them in social security. According to Empower Sex Worker Member 4:

Before Can Do we all thought we couldn't join social security. Our bosses also said it was impossible. But now we know differently. Social security? Can Do!

As a result of our many successes, the Can Do Bar has been called a model intervention by Henny Ngu at the UNDP and has received further national and international recognition as demonstrated by visits from Thai Ministries of Labor and Social Welfare, National Human Rights Commission, UNAIDS, the International Labor Organization, and students, researchers, journalists, and others from around the world, all of whom have come to learn from our model. We also received funding from Mama Cash, American Jewish World Service, Red Umbrella Fund, and many others.

Perhaps most importantly, Can Do creates collective community pride as our members have proven that safe, fair sex work is possible. Overall, Empower and the Can Do Bar present a clear message: interventions focusing only on disease, especially HIV/STI prevention, ignore other OHS issues that are equally important to women. Instead, supporting women to organise and make changes that they identify as important and necessary can create healthy and just working conditions for sex workers and serve as a model for other establishments.

\section{Lessons from Empower and Beyond: Best Practices to Reduce Harm, Promote Health, and Advance Rights for Indoor Sex Workers}

Given the range of health and safety issues sex workers confront as part of their daily lives, a focus on improving working environments and supporting safer sex work spaces is crucial to ensuring the rights of sex workers. Perhaps more than outdoor venues, indoor venues are in a unique position to utilise such an approach, though OHS issues and needs will vary by venue and context. Broadly speaking, sex workers deserve access to healthy and risk-free work environments where they have decision-making power, their physical and psychological safety is ensured, and they have recourse when they experience harm in the workplace. Without structural changes to the policy context, however, creating such environments is 
challenging [78]. The following section details recommended best practices for indoor sex work venues.

First, indoor sex work venues can be made safer for sex workers by prioritising occupational health and safety and harm reduction. Many sex workers, including those from Empower, as well sex worker organisations and activists, endorse an explicit focus on OHS as a starting point for supporting sex workers. This requires recognition that sex work is work and therefore sex workers need labour rights. An OHS perspective involves preventing day-to-day workplace exposures and hazards, treating injuries and disease, holding employer's accountable for the health and safety of employees, and promoting worker rights to mitigate harms associated with disproportionate disease burden, substance use, exposure to violence, debt, exploitation, and marginalisation $[15,79]$.

OHS in indoor venues involves a combination of employer duties, working conditions, protection and prevention, and care and support [79]. Venue owners and managers have a responsibility to consult with employees to identify hazards, address harms and to assess and control risk by, for example, screening and refusing clients; providing good lighting, panic buttons, and hygiene materials like soap, water, clean linens, and towels; keeping the environment clean and well maintained; and providing information and supplies for safer sex and safer drug use $[9,24,25,27-30]$. Managers must support access to regular health screenings and services, including the management of STIs, HIV, cervical and anogenital cancer, Hepatitis B and C, tuberculosis, as well as access to a range of contraceptive options, safe abortions, and post-abortion care [80]. Importantly, work environments should be free of coercion of any sort, including freedom from any requirement to have sex without a condom, and the freedom to refrain from drinking or using drugs. If needed, work environments should also provide support to workers in using substances safely, if needed (e.g. provision of drugrelated harm reduction information, free clean syringes, naloxone, and fentanyl test strips) [79]. Beyond this, wider support for sex worker health and safety issues should include violence prevention tools, and managerial support for employees to organise, join unions, and access a range of health and social services [80].

Proper working conditions include reasonable work schedules with adequate breaks, vacations, and leaves, but should also include the provision of workers' compensation, insurance, and legal support, plus ensure that workers are able to report accidents or injuries, and hold employers accountable when sex workers' rights and safety are violated [79]. Importantly, OHS measures must be cognisant of the diversity of sex workers' lived experience and concerns [80]. This involves focusing on how to make venues more inclusive of marginalised sex workers-including people who use drugs, immigrants/migrants and transgender sex workers- to more fully advance the rights and safety of sex workers. For instance, migrant sex workers may have need for translation or legal services. For people who use substances, access to treatment for drug, alcohol, and tobacco dependence is crucial to supporting health and safety [80]. For transgender sex 
workers, special attention to both physical and mental health needs, as well as additional safety protections, could make indoor venues healthier and safer spaces that are also more welcoming.

Second, strengthening the rights and health of indoor sex workers requires their full and meaningful engagement. This involves a host of activities including support for community organising, sex worker-led initiatives, and mobilisation and empowerment efforts. Sex workers are too often left out of the discussions that impact their lives. Yet, as seen in the innovative work of Empower Thailand, sex workers are strategic partners to improve health and rights and are the experts in their own work and needs $[81,82]$. Including sex workers should be an integral part of all phases of research and intervention, including design, planning, implementation, and evaluation. Given that sex workers already use diverse strategies of risk mitigation to navigate physical spaces and client relationships, their agency should be respected and built upon to move towards respectful, sustainable, realistic, and effective solutions.

In indoor venues, community empowerment and mobilisation efforts have been employed in various ways reflecting the diverse needs of sex workers at both the individual and structural level. Within such venues, the promotion of collective efficacy in the form of sex workers looking out for each other can be incredibly protective and supportive. Connection, even in informal ways, can help to promote self-efficacy, self-esteem, negotiation skills, and personal safety skills, all of which have been shown to reduce the risk of HIV/STI, experiences of violence, alcohol and substance use, and debt [79]. Peer education within venues - or the use of peer workers for outreach (or "in-reach", as described by Empower) - can also build community among sex workers and be an effective tool for conveying health and safety information [83]. For example, Stella, a sex worker organisation in Montreal, produces working, safety, and rights guides designed by and for sex workers, including specific guides for strippers, clients, and people who use drugs [84].

The establishment of peer-run and led sex worker collectives, like Empower and others, represents a powerful model for community organising. For instance, sex worker collectives play a major role in the promotion of OHS as they often help people navigate exploitative or coercive working conditions and/or problems with venue managers, owners, or landlords. This is important as sex workers typically do not have legal support when making complaints against employers and often do not want to damage relationships with management [84]. Sex worker collectives can instead leverage their collective power to put pressure on operators to improve working conditions or work collaboratively to establish better business practices [84]. More broadly, greater ownership and management of sex working spaces, like the Can Do Bar, can be incredibly important for ensuring that sex workers have safe and equitable working conditions.

Community mobilisation and advocacy are also fundamental to addressing rights abuses against sex workers [85]. Sex worker collectives and rights organisations have played a substantial role in fighting the policies that threaten the health and safety of indoor sex workers. Organisations like the Bar Hostess 
Empowerment and Support Programme (BHESP) in Nairobi used their collective power to confront violence by going to the courts and publicly advocating against police and client brutality [86]. Similarly, Empower Thailand organised to draw attention to police raids of indoor venues and entrapment practices that violate sex worker rights, and are fighting for decriminalisation. Such efforts have been successful. In New Zealand, the New Zealand Prostitutes Collective (NZPC), established by a small group of indoor sex workers, was at the forefront of decriminalisation efforts in the country and they continue to use their power to support migrant sex workers, who remain criminalised under the Prostitution Reform Act.

As these examples show, community empowerment-through peer leadership, collectivisation, mobilisation, and advocacy - is a form of social justice. It is both a social process and a structural intervention that challenges the diverse factors undermining sex workers' rights and equality [83, 87]. Importantly, the breadth and success of these efforts stems directly from the centering of sex worker expertise and control. To ensure that interventions are effective and responsive to sex worker needs, it is therefore imperative that sex workers have meaningful ownership over interventions. Interventions that bridge communityled processes with structural targets-aiming to alter the very power relations that lead to inequities $[41,88]$ — show great promise for effectively supporting sex workers to achieve the goals that are most important to them.

Third, explicit attention must be given to changing punitive policies that affect the health and rights of sex workers and third parties in indoor venues. Widespread support for the OHS of sex workers has been limited by the criminalisation and coercive regulation of sex work, as well as by moral discourses denigrating individuals for the work they do [49]. Shifting the policy environment and countering stigmatising practices are essential components of supporting sex workers, both within indoor venues and in other spaces.

There is consensus among sex work activists and public health and human rights organisations (e.g. UNAIDS, WHO, Amnesty International) that full decriminalisation of all aspects of sex work is essential to promote the health and human rights of sex workers [89-91]. This includes not only sex workers, clients, and third parties, but also those indirectly associated with sex work, such as hairdressers, taxi drivers and the children of sex workers. In contexts such as New Zealand, where sex work has been fully decriminalised (but only for New Zealand citizens), research demonstrates many successes in terms of making sex work safer and improving rights across various sectors of the sex industry [92]. In Rhode Island in the United States, when indoor sex work was decriminalised, the indoor sex market increased in size, suggesting a shift away from more dangerous outdoor settings, and rape offences and gonorrhoea incidence substantially decreased [93]. Conversely, where changes in sex work regulation have made it harder to conduct sex work in indoor spaces - as in the 2018 legislation in the United States cracking down on online solicitation - the carrying out of sex work was pushed to often riskier outdoor, isolated, or less visible spaces [49, 65]. Evidence from countries or cities where sex work is partially decriminalised 
suggests that such measures can open doors to greater safety, but quasi-criminalisation still poses challenges to the full actualisation of sex workers' rights, and to control over their bodies, working conditions, and safety [50].

Even in contexts without federal or state decriminalisation, changes in municipal laws or policing practices can have significant impacts on health and safety $[4,65,94]$. Such changes involve, among other things, putting an end to the targeting of public solicitation, stopping workplace raids, eliminating sex work licensing practices or high fees for licences, getting rid of employee registration requirements, and helping sex workers to deal with violent clients.

Additionally, working with police to change their treatment of sex workers, with emphasis on the provision of support, rather than the practices of abuse or arrest, could make the everyday lives of sex workers safer [94]. Sex worker collectives are especially important to this process, as they are a powerful force when it comes to creating change and holding law enforcement bodies accountable for their actions against sex workers [94].

\section{Conclusions}

This chapter highlights how physical, economic, social, and policy contexts shape the health, rights, and safety outcomes of indoor sex workers (see Fig. 12.1). Understanding the variety of spaces in which people work and how the characteristics of sex work venues impact health and safety is essential to developing interventions, programmes, and policies that support sex worker needs. Attention to indoor venues is especially important because these spaces have greater potential for establishing OHS standards, and also may provide substantial opportunity for collective organising given the close proximity of people working together. However, any efforts to improve the health and safety of sex workers must explicitly address the structural conditions that lead to power imbalances and which undermine sex worker agency and equality.

Broadly, the physical spaces in which sex work is conducted-including aspects of the built environment, workplace policies, and managerial practices-play a key role in determining working conditions within indoor sex work establishments. Economic factors like debt and financial exploitation can undermine sex workers' autonomy, safety, and their ability to negotiate with clients, as can power imbalances and stigma. Relationships with others in sex work, such as peers, owners, and managers, have the power to be beneficial or harmful, depending on the dynamics within the indoor venue. Underlying all of this, legal factors, especially criminalisation and punitive policing practices, challenge sex workers' ability to protect themselves and establish safer work environments. However, as discussed, these factors often interact in ways that create complex challenges to health and safety on multiple fronts. For instance, criminalisation and stigma often stand in the way of community mobilisation and, even though OHS approaches can be implemented in punitive legal contexts, criminalisation means that such efforts are unlikely to be 


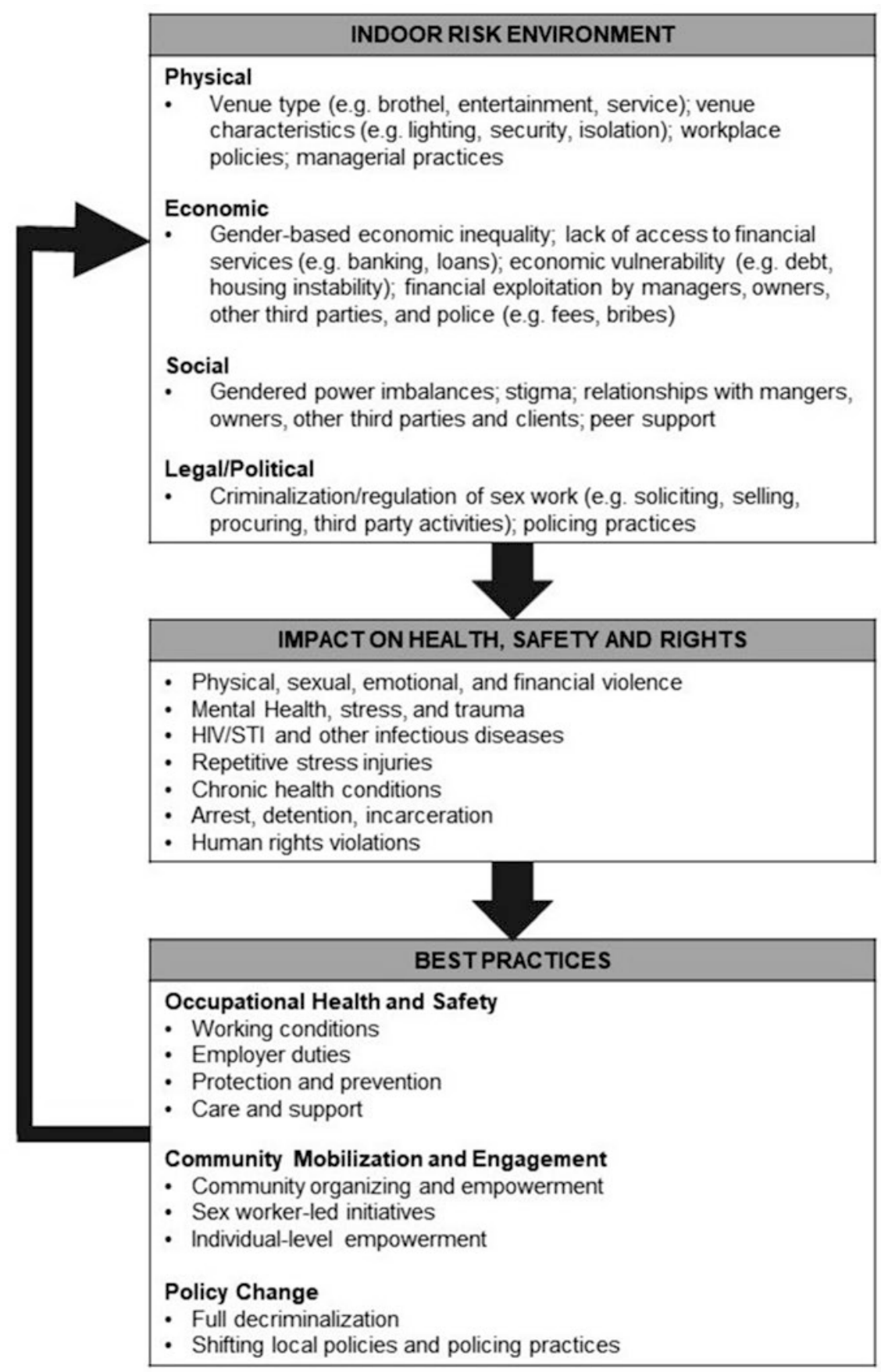

Fig. 12.1 Conceptual framework of indoor sex work risk environments, effects on health and safety, and best practices 
supported by labour laws holding employers accountable, leaving sex workers still without the necessary safeguards to protect their health [80, 92].

Given the structural nature of these threats to the health and safety of sex workers working in indoor venues, there is a need to challenge existing power structures and to advance sex worker rights. This includes promoting occupational health and safety, focusing on community mobilisation and engagement, and fighting for changes to punitive policies. A focus on these practices could directly impact sex workers' health and rights, while also shifting the risk environment in which sex work occurs, to reduce the harms associated with this work. However, individuals affected by interventions and policies geared towards sex work are too often left out of the conversations that impact their lives. Moving forward, the approach of "nothing about us, without us" must be prioritised and ultimately realised. Anything less serves as a continuation of the stigma and human rights violations that already unjustly plague communities of sex workers around the world.

\section{References}

1. Rhodes T. The 'risk environment': a framework for understanding and reducing drug-related harm. Int J Drug Policy. 2002;13(2):85-94.

2. Strathdee SA, Hallett TB, Bobrova N, Rhodes T, Booth R, Abdool R, et al. HIV and risk environment for injecting drug users: the past, present, and future. Lancet. 2010;376(9737):268-84.

3. Pitpitan EV, Kalichman SC, Eaton LA, Strathdee SA, Patterson TL. HIV/STI risk among venue-based female sex workers across the globe: a look back and the way forward. Curr HIV/ AIDS Rep. 2013;10(1):65-78.

4. Deering K, Lyons T, Feng C, Nosyk B, Strathdee S, Montaner J, et al. Client demands for unsafe sex: the socio-economic risk environment for HIV among street and off-street sex workers. J Acquir Immune Defic Syndr. 2013;63(4):522.

5. Shannon K, Strathdee SA, Shoveller J, Rusch M, Kerr T, Tyndall MW. Structural and environmental barriers to condom use negotiation with clients among female sex workers: implications for HIV-prevention strategies and policy. Am J Public Health. 2009;99(4):659-65.

6. Shannon KKT, Strathdee SA, Shoveller J, Montaner JS, Tyndall MW. Prevalence and structural correlates of gender based violence among a prospective cohort of female sex workers. BMJ. 2009;339:b2939.

7. Church S, Henderson M, Barnard M, Hart G. Violence by clients towards female prostitutes in different work settings: questionnaire survey. BMJ. 2001;322(7285):524-5.

8. Shannon KKT, Allinott S, Chettiar J, Shoveller J, Tyndall MW. Social and structural violence and power relations in mitigating HIV risk of drug-using women in survival sex work. Soc Sci Med. 2008;66:911-21.

9. Krusi A, Chettiar J, Ridgway A, Abbott J, Strathdee S, Shannon K. Negotiating safety and sexual risk reduction with clients in unsanctioned safer indoor sex work environments: a qualitative study. Am J Public Health. 2012;102:1154-9.

10. Scorgie F, Vasey K, Harper E, Richter M, Nare P, Maseko S, et al. Human rights abuses and collective resilience among sex workers in four African countries: a qualitative study. Global Health. 2013;9(1):33.

11. Harcourt C, Donovan B. The many faces of sex work. Sex Transm Infect. 2005;81(3):201-6.

12. Shannon K, Csete J. Violence, condom negotiation, and HIV/STI risk among sex workers. JAMA. 2010;304(5):573-4. 
13. Hampanda K. The social dynamics of selling sex in Mombasa, Kenya: a qualitative study contextualizing high risk sexual behaviour. Afr J Reprod Health. 2013;17(2):141-9.

14. Prior J, Hubbard P, Birch P. Sex worker victimization, modes of working, and location in New South Wales, Australia: a geography of victimization. J Sex Res. 2013;50(6):574-86.

15. Alexander P. Sex work and health: a question of safety in the workplace. J Am Med Womens Assoc. 1998;53(2):77-82.

16. Thoits PA. Stress and health: major findings and policy implications. J Health Soc Behav. 2010;51(1_suppl):S41-53.

17. Ross MW, Crisp BR, Månsson S-A, Hawkes S. Occupational health and safety among commercial sex workers. Scand J Work Environ Health. 2012;38:105-19.

18. Bungay V, Guta A. Strategies and challenges in preventing violence against Canadian indoor sex workers. Am J Public Health. 2018;108(3):393-8.

19. Goldenberg SM, Duff P, Krusi A. Work environments and HIV prevention: a qualitative review and meta-synthesis of sex worker narratives. BMC Public Health. 2015;15(1):1241.

20. Puri N, Shannon K, Nguyen P, Goldenberg S. Burden and correlates of mental health diagnoses among sex workers in an urban setting. BMC Womens Health. 2017;17(1):133.

21. Duff P, Sou J, Chapman J, Dobrer S, Braschel M, Goldenberg S, Shannon K. Poor working conditions and work stress among Canadian sex workers. Occup Med. 2017;67(7):515-21.

22. McBride B, Shannon K, Duff P, Mo M, Braschel M, Goldenberg SM. Harms of workplace inspections for im/migrant sex workers in in-call establishments: enhanced barriers to health access in a Canadian setting. J Immigr Minor Health. 2019;21(6):1290-9.

23. Duff P, Shoveller J, Dobrer S, Ogilvie G, Montaner J, Chettiar J, et al. The relationship between social, policy and physical venue features and social cohesion on condom use for pregnancy prevention among sex workers: a safer indoor work environment scale. J Epidemiol Community Health. 2015;69(7):666-72.

24. Maher L, Mooney-Somers J, Phlong P, Couture MC, Stein E, Evans J, et al. Selling sex in unsafe spaces: sex work risk environments in Phnom Penh, Cambodia. Harm Reduct J. 2011;8:30.

25. Phrasisombath K, Faxelid E, Sychareun V, Thomsen S. Risks, benefits and survival strategiesviews from female sex workers in Savannakhet, Laos. BMC Public Health. 2012;12(1):1004.

26. Urada LA, Morisky DE, Hernandez LI, Strathdee SA. Social and structural factors associated with consistent condom use among female entertainment workers trading sex in the Philippines. AIDS Behav. 2013;17(2):523-35.

27. Chen Y, Latkin C, Celentano DD, Yang X, Li X, Xia G, et al. Delineating interpersonal communication networks: a study of the diffusion of an intervention among female entertainment workers in Shanghai, China. AIDS Behav. 2012;16(7):2004-14.

28. Ghose T, Swendeman DT, George SM. The role of brothels in reducing HIV risk in Sonagachi, India. Qual Health Res. 2011;21(5):587-600.

29. Hao C, Guida J, Morisky DE, Liu H. Family network, workplace network, and their influence on condom use: a qualitative study among older female sex workers in China. J Sex Res. 2015;52(8):924-35.

30. Buzdugan R, Halli S, Hiremath J, Jayanna K, Raghavendra T, Moses S, et al. The female sex work industry in a district of India in the context of HIV prevention. AIDS Res Treat. 2012;2012(371482):10.

31. Evans C, Lambert H. The limits of behaviour change theory: condom use and contexts of HIV risk in the Kolkata sex industry. Cult Health Sex. 2008;10(1):27-41.

32. Goldenberg SM, Strathdee SA, Gallardo M, Nguyen L, Lozada R, Semple SJ, et al. How important are venue-based HIV risks among male clients of female sex workers? A mixed methods analysis of the risk environment in nightlife venues in Tijuana, Mexico. Health Place. 2011;17(3):748-56.

33. Gilmour F. Work conditions and job mobility in the Australian indoor sex industry. Sociol Res Online. 2016;21(4):1-2. 
34. Harcourt C, van Beek I, Heslop J, McMahon M, Donovan B. The health and welfare needs of female and transgender street sex workers in New South Wales. Aust N Z J Public Health. 2001;25(1):84-9.

35. Reed E, Gupta J, Biradavolu M, Devireddy V, Blankenship KM. The context of economic insecurity and its relation to violence and risk factors for HIV among female sex workers in Andhra Pradesh, India. Public Health Rep. 2010;125(Suppl 4):81-9.

36. Ntumbanzondo M, Dubrow R, Niccolai LM, Mwandagalirwa K, Merson MH. Unprotected intercourse for extra money among commercial sex workers in Kinshasa, Democratic Republic of Congo. AIDS care. 2006;18(7):777-85.

37. Choi S. Heterogeneous and vulnerable: the health risks facing transnational female sex workers. Sociol Health Illn. 2011;33(1):33-49.

38. Reed E, Gupta J, Biradavolu M, Devireddy V, Blankenship K. The role of housing in determining HIV risk among female sex workers in Andhra Pradesh, India: considering women's life contexts. Soc Sci Med. 2011;72(5):710-6.

39. Reed E, Silverman J, Stein B, Erausquin J, Biradavolu M, Rosenberg A, et al. Motherhood and HIV risk among female sex workers in Andhra Pradesh, India: the need to consider women's life contexts. AIDS Behav. 2013;17(2):543-50.

40. Urada L, Morisky D, Pimentel-Simbulan N, Silverman J, Strathdee S. Condom negotiations among female sex workers in the Philippines: environmental influences. PLoS One. 2012;7(3):e33282.

41. Blankenship K, West B, Kershaw T, Biradavolu M. Power, community mobilization, and condom use practices among female sex workers in Andhra Pradesh, India. AIDS. 2008;22(Suppl 5):S109-S16.

42. Yi H, Zheng T, Wan Y, Mantell J, Park M, Csete J. Occupational safety and HIV risk among female sex workers in China: a mixed-methods analysis of sex-work harms and mommies. Glob Public Health. 2012;7(8):840-55.

43. Erausquin JT, Reed E, Blankenship KM. Police-related experiences and HIV risk among female sex workers in Andhra Pradesh, India. J Infect Dis. 2011;204(Suppl 5):S1223-8.

44. Damacena G, Szwarcwald C, de Souza P, Dourado I. Risk factors associated with HIV prevalence among female sex workers in 10 Brazilian cities. J Acquir Immune Defic Syndr. 2011;57:S144-S52.

45. Gaines T, Rusch M, Brouwer K, Lozada R, Perkins E, Strathdee S, et al. The effect of geography on HIV and sexually transmitted infections in Tijuana's red light district. J Urban Health. 2013;90(5):915-20.

46. O’Doherty T. Victimization in off-street sex industry work. Violence Against Women. 2011;17(7):944-63.

47. Benoit C, Millar A. Dispelling myths and understanding realities: working conditions, health status, and exiting experiences of sex workers. Victoria, BC: BC Health Research Foundation; 2001.

48. Comte J. Decriminalization of sex work: feminist discourses in light of research. Sex Cult. 2014;18(1):196-217.

49. Shannon K, Strathdee SA, Goldenberg SM, Duff P, Mwangi P, Rusakova M, et al. Global epidemiology of HIV among female sex workers: influence of structural determinants. Lancet. 2015;385(9962):55-71.

50. Deering KN, Amin A, Shoveller J, Nesbitt A, Garcia-Moreno C, Duff P, Argento E, Shannon K. A systematic review of the correlates of violence against sex workers. Am J Public Health. 2014;104(5):e42-54.

51. Liu Q, Zhuang K, Henderson G, Shenglong Q, Fang J, Yao H, et al. The organization of sex work in low-and high-priced venues with a focus on the experiences of ethnic minority women working in these venues. AIDS Behav. 2014;18(2):172-80.

52. Cheng SS, Mak WW. Contextual influences on safer sex negotiation among female sex workers (FSWs) in Hong Kong: the role of non-governmental organizations (NGOs), FSWs' managers, and clients. AIDS Care. 2010;22(5):606-13. 
53. Januraga P, Mooney-Somers J, Ward P. Newcomers in a hazardous environment: a qualitative inquiry into sex worker vulnerability to HIV in Bali, Indonesia. BMC Public Health. 2014;14(1):832.

54. Bungay V, Halpin M, Halpin P, Johnson C, Patrick D. Violence in the massage parlor industry: experiences of Canadian-born and immigrant women. Health Care Women Int. 2012;33(3):262-84.

55. Handlovsky I, Bungay V, Kolar K. Condom use as situated in a risk context: women's experiences in the massage parlour industry in Vancouver, Canada. Cult Health Sex. 2012;14(9):1007-20.

56. Howard S. Better health for sex workers: which legal model causes least harm? BMJ. 2018;361:k2609.

57. McCarthy B, Benoit C, Jansson M, Kolar K. Regulating sex work: heterogeneity in legal strategies. Annu Rev Law Soc Sci. 2012;8:255-71.

58. Peterson M, Robinson B, Shih E. The new virtual crackdown on sex workers' rights: perspectives from the United States. Anti-Traffick Rev. 2019;12:189-93.

59. McBride B, Goldenberg SM, Murphy A, Wu S, Braschel M, Krüsi A, et al. Third parties (venue owners, managers, security, etc.) and access to occupational health and safety among sex workers in a Canadian setting: 2010-2016. Am J Public Health. 2019;109:792-8.

60. Sanders T, Campbell R. Designing out vulnerability, building in respect: violence, safety and sex work policy. Br J Sociol. 2007;58(1):1-19.

61. Anderson S, Shannon K, Li J, Lee Y, Chettiar J, Goldenberg S, et al. Condoms and sexual health education as evidence: impact of criminalization of in-call venues and managers on migrant sex workers access to HIV/STI prevention in a Canadian setting. BMC Int Health Hum Rights. 2016;16(1):30.

62. Beyrer C, Crago A-L, Bekker L-G, Butler J, Shannon K, Kerrigan D, et al. An action agenda for HIV and sex workers. Lancet. 2015;385(9964):287-301.

63. Decker MR, Crago A-L, Chu SK, Sherman SG, Seshu MS, Buthelezi K, et al. Human rights violations against sex workers: burden and effect on HIV. Lancet. 2015;385(9963):186-99.

64. Rhodes T, Simic M, Baros S, Platt L, Zikic B. Police violence and sexual risk among female and transvestite sex workers in Serbia. BMJ. 2008;337:a811.

65. Anderson S, Jia J, Liu V, Chattier J, Krüsi A, Allan S, et al. Violence prevention and municipal licensing of indoor sex work venues in the Greater Vancouver Area: narratives of migrant sex workers, managers and business owners. Cult Health Sex. 2015;17(7):825-41.

66. Plumridge L, Abel G. A 'segmented' sex industry in New Zealand: sexual and personal safety of female sex workers. Aust N Z J Public Health. 2001;25(1):78-83.

67. Shannon K, Rusch M, Shoveller J, Alexson D, Gibson K, Tyndall MW. Mapping violence and policing as an environmental-structural barrier to health service and syringe availability among substance-using women in street-level sex work. Int J Drug Policy. 2008;19(2):140-7.

68. Azim T, Bontell I, Strathdee SA. Women, drugs and HIV. Int J Drug Policy. 2015;26:S16-21.

69. Goldenberg S, Krusi A, Zhang E, Chettiar J, Shannon K. Structural determinants of health among im/migrants in the indoor sex industry: experiences of workers and managers/owners in Metropolitan Vancouver. PLoS One. 2017;12(1):e0170642.

70. Goldenberg SM, Jiménez TR, Brouwer KC, Miranda SM, Silverman JG. Influence of indoor work environments on health, safety, and human rights among migrant sex workers at the Guatemala-Mexico Border: a call for occupational health and safety interventions. BMC Int Health Hum Rights. 2018;18(1):9.

71. Richter M, Chersich MF, Vearey J, Sartorius B, Temmerman M, Luchters S. Migration status, work conditions and health utilization of female sex workers in three South African cities. J Immigr Minor Health. 2014;16(1):7-17.

72. Richter M, Chersich M, Temmerman M, Luchters S. Characteristics, sexual behaviour and risk factors of female, male and transgender sex workers in South Africa. S Afr Med J. 2013;103(4):246-51.

73. Logie C, James L, Tharao W, Loutfy M. HIV, gender, race, sexual orientation, and sex work: a qualitative study of intersectional stigma experienced by HIV-positive women in Ontario, Canada. PLoS Med. 2011;8:e1001124. 
74. Hwahng S, Nuttbrock L. Sex workers, fem queens, and cross-dressers: differential marginalizations and HIV vulnerabilities among three ethnocultural male-to-female transgender communities in New York City. Sex Res Soc Policy. 2007;4:36-59.

75. Prado Cortez F, Boer D, Baltieri D. A psychosocial study of male-to-female transgendered and male hustler sex workers in São Paulo, Brazil. Arch Sex Behav. 2011;40:1223-31.

76. Poteat T, Wirtz A, Radix A, Borquez A, Silva-Santisteban A, Deutsch M, et al. HIV risk and preventive interventions in transgender women sex workers. Lancet. 2015;385(9964):274-86.

77. Lyons T, Krüsi A, Pierre L, Kerr T, Small W, Shannon K. Negotiating violence in the context of transphobia and criminalization: the experiences of trans sex workers in Vancouver, Canada. Qual Health Res. 2017;27(2):182-90.

78. Victoria CA. Occupational health and safety (OHS) and cleaning your sex work premises. 2019. Available from: https://www.consumer.vic.gov.au/ licensing-and-registration/sex-work-service-providers/running-your-business/ occupational-health-and-safety-and-cleaning.

79. Rekart ML. Sex-work harm reduction. Lancet. 2005;366(9503):2123-34.

80. ICRSE. Understanding sex workers' right to health: impact of criminalisation and violence. Amsterdam: International Committee on the Rights of Sex Workers in Europe; 2017.

81. Basnyat I. Lived experiences of street-based female sex workers in Kathmandu: implications for health intervention strategies. Cult Health Sex. 2014;16(9):1040-51.

82. Sanders T, Hardy K, Campbell R. Regulating strip-based entertainment: sexual entertainment venue policy and the ex/inclusion of dancers' perspectives and needs. Soc Policy Soc. 2015;14(1):83-92.

83. Awungafac G, Delvaux T, Vuylsteke B. Systematic review of sex work interventions in sub-Saharan Africa: examining combination prevention approaches. Trop Med Int Health. 2017;22(8):971-93.

84. GAATW. Sex workers organizing for change: self-representation, community mobilisation, and working conditions. Bangkok, Thailand: Global Alliance Against Traffic in Women (GAATW); 2018.

85. Evans C, Jana S, Lambert H. What makes a structural intervention? Reducing vulnerability to HIV in community settings, with particular reference to sex work. Glob Public Health. 2010;5(5):449-61.

86. Kerrigan D, Kennedy CE, Morgan-Thomas R, Reza-Paul S, Mwangi P, Win KT, et al. A community empowerment approach to the HIV response among sex workers: effectiveness, challenges, and considerations for implementation and scale-up. Lancet. 2015;385(9963):172-85.

87. Kerrigan D, Fonner V, Stromdahl S, Kennedy C. Community empowerment among female sex workers is an effective HIV prevention intervention: a systematic review of the peer-reviewed evidence from low-and middle-income countries. AIDS Behav. 2013;17(6):1926-40.

88. Gupta G, Parkhurst J, Ogden J, Aggleton P, Mahal A. Structural approaches to HIV prevention. Lancet. 2008;372(9640):764-75.

89. World Health Organization. Consolidated guidelines on HIV prevention, diagnosis, treatment and care for key populations. Geneva, Switzerland: World Health Organization; 2016.

90. Godwin J. Sex work and the law in Asia and the Pacific: laws, HIV and human rights in the context of sex work. Geneva, Switzerland: UNAIDS, UNFPA, UNDP; 2012.

91. Amnesty International publishes policy and research on protection of sex workers' rights [press release]. 26 May 2016.

92. Abel G. A decade of decriminalization: sex work 'down under' but not underground. Criminol Crim Just. 2014;14(5):580-92.

93. Cunningham S, Shah M. Decriminalizing indoor prostitution: implications for sexual violence and public health. Rev Econ Stud. 2017;85(3):1683-715.

94. Gaines TL, Rusch ML, Brouwer KC, Goldenberg SM, Lozada R, Robertson AM, et al. Venue-level correlates of female sex worker registration status: a multilevel analysis of bars in Tijuana, Mexico. Glob Public Health. 2013;8(4):405-16. 
Open Access This chapter is licensed under the terms of the Creative Commons Attribution 4.0 International License (http://creativecommons.org/licenses/by/4.0/), which permits use, sharing, adaptation, distribution and reproduction in any medium or format, as long as you give appropriate credit to the original author(s) and the source, provide a link to the Creative Commons license and indicate if changes were made.

The images or other third party material in this chapter are included in the chapter's Creative Commons license, unless indicated otherwise in a credit line to the material. If material is not included in the chapter's Creative Commons license and your intended use is not permitted by statutory regulation or exceeds the permitted use, you will need to obtain permission directly from the copyright holder. 